\title{
NOTAS SOBRE SUFIJOS DE ORIGEN GRIEGO EN ESPAÑOL
}

Jorge Bergua Cavero

Universidad de Málaga

\section{RESUMEN}

El artículo es una revisión crítica del libro de David Pharies, Diccionario etimológico de los sufijos españoles y otros elementos finales; revisión centrada en los sufijos que tienen una relación más o menos directa con el griego clásico. El autor trata de señalar algunos errores o lagunas en lo que se refiere a la identificación, historia, acentuación, etc., de dichos sufijos, aprovechando de paso para proponer algunos posibles temas que quedarian por investigar en este campo tan amplio.

Ya se venía haciendo notar la ausencia de un estudio más o menos completo sobre la sufijación en español con una orientación histórico-etimológica y no sincrónica; por eso hay que felicitarse por la publicación de este amplio y cuidado diccionario (Madrid, Gredos, 2002). Vamos a hacer algunas observaciones al respecto, centrándonos en aquello que conocemos mejor, los sufijos españoles relacionados con el griego clásico '.

1 Remitiremos en más de una ocasión a nuestra Introducción al estudio de los helenismos del español, Zaragoza, 2002, pues allí (en $\$ 12.2$, págs. 207-270) tratamos de hacer algo similar a lo que hace Pharies (sólo con los sufijos de origen griego). 
El autor deja bien claro en su introducción las razones que le han llevado a escribir esta obra, y a hacerlo de la forma en que lo ha hecho. La razón fundamental es, desde luego, la poca atención prestada a la sufijación en las obras de etimología y gramática histórica del español, de lo que pueden valer como ejemplos representativos el diccionario etimológico de J. Corominas o la gramática histórica de M. Alvar y B. Pottier; en muchos aspectos las obras de W. Meyer-Lübke (Grammaire des langues romanes, vol. 2, París, 1895) y J. Alemany Bolufer (Ensayo sobre la formación de palabras en español, Madrid, 1920), siguen siendo el mejor tratamiento del tema en su dimensión histórica. Ello contrasta con la abundancia y calidad de estudios de carácter sincrónico sobre la formación de palabras (especialmente el de F. Rainer, Spanische Wortbildungslehre, Tubinga, 1993).

En este sentido, era difícil encontrar en los diccionarios o las gramáticas información fiable sobre el origen, vías de entrada y difusión histórica de los principales sufijos españoles, como tuvimos ocasión de comprobar repetidamente al escribir nuestra obra sobre los helenismos mencionada (que, desde luego, se hubiera beneficiado mucho de este diccionario de haber podido utilizarlo, sobre todo por lo que se refiere al material fechado del español medieval y moderno). Una dificultad que se ve agravada por la ausencia de un buen diccionario histórico del español del estilo del Oxford English Dictionary o el Trésor de la langue française, y en general, como no deja de señalar Pharies, por el hecho de que «la datación del vocabulario español deja mucho que desear» (pág. 15).

Como dice el autor, «un diccionario etimológico no es lo mismo que uno histórico. Aquél puede limitarse, por ejemplo, a la identificación de un precursor de una unidad léxica, sin ocuparse de los cambios fonéticos, morfológicos y semánticos que hayan podido intervenir entre los dos. En cambio, el diccionario histórico se propone explicar la totalidad de la evolución de un elemento desde un determinado punto del pasado hasta el presente» (pág. 14). Y efectivamente, que -cuando van más allá del nivel escolar - suelen ser meramente etimológicos y dejan sin explicar un gran número de cuestiones que afectan a la vía de entrada de la palabra en español, su transcripción y acentuación, su adaptación fonotáctica o morfológica, su composición o derivación, su evolución semántica, etc. Desde este punto de vista, el diccionario de Pharies va mucho más allá, pues es «primordialmente etimológico, pero con pretensiones de ser, en lo posible, histórico" (pág. 14), facilitando valiosa información sobre la primera documentación, la procedencia y vía de entrada de los sufijos, el papel desempeñado por otras lenguas (sobre todo el francés), etc.

Como el mismo título indica, el diccionario incluye no sólo sufijos sino también «otros elementos finales» no propiamente derivativos, en su mayoría 
lexemas cultos griegos y en menor medida latinos (-'fugo, - fago, etc.), que reciben diversos nombres en la bibliografía sobre formación de palabras (sufijoides, combinemas cultos, etc. $)^{2}$. Pharies se encarga de dejar bien claras algunas de las diferencias que separan tales elementos de los sufijos propiamente dichos: su carga semántica es léxica, muchos pueden aparecer en posición inicial, etc. Ello podría justificar sin más su exclusión, pero su aparición en el diccionario tiene al menos una ventaja que no suelen tener otras obras sobre helenismos -donde estos elementos parecen seleccionados un poco al azar-, y es que al menos aquí se incluyen con un criterio claro: su aparición en un mínimo de cinco casos. Aparecen recogidos unos ochenta elementos griegos de este tipo (-agogo, -algia, -ántropo, -arca, -céfalo, etc.), sobre los que no hay mucho que comentar, excepto quizá un par de aclaraciones sobre -'crata y -'geno y una breve nota referente a la acentuación.

Sobre -'crata: Pharies menciona para autócrata, aristócrata y timócrata

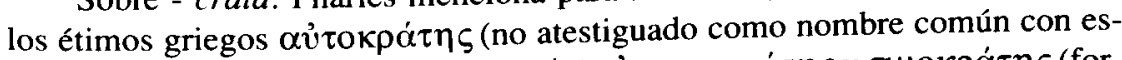

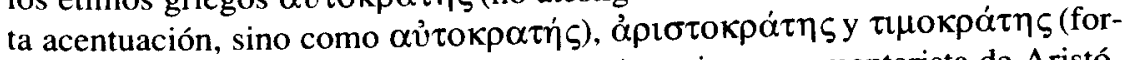
maciones muy raras, atestiguadas sólo en Aspasio, un comentarista de Aristóteles; sólo son frecuentes como nombres propios: Aristócrates, Timócrates). Si tenemos en cuenta que en francés aristocrate, por ejemplo, se documenta ya en 1550 , aunque no se haga común hasta el siglo XVIII, se plantea aquí una duda que no deja de revestir interés: las formas francesas como aristocrate o timocrate (que sin duda han servido de modelo a las españolas correspondientes, como parece indicar la terminación española en $-a<\mathrm{fr} .-e)$, ¿proceden real-

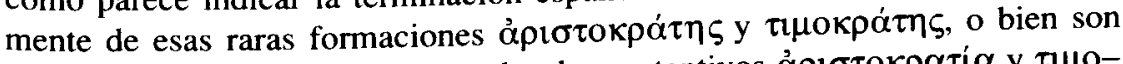

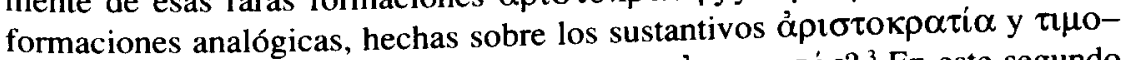
$\kappa \rho \alpha \tau i \alpha$ siguiendo el modelo de autocrate $>\alpha \dot{\tau} \tau o \kappa \rho \alpha \tau \dot{\eta} \zeta ?{ }^{3}$ En este segundo supuesto, estaríamos ante unas formas francesas espontáneamente acuñadas sin conocer las formas griegas correspondientes, como ha ocurrido en algún otro caso (lo que es indicio de hasta qué punto las lenguas modernas han asimilado y hecho propio el sistema de derivación y composición del griego) ${ }^{4}$.

En cuanto a -'geno, este formante no está debidamente explicado en la entrada de Pharies, quien, dejándose confundir por voces de origen latino como alienígenola, terrígenola, etc., lo toma por una terminación «de origen pri-

2 Cf. Bergua, ob. cit., págs. 271-275.

Del mismo modo que demócrata es formación analógica a partir de $\delta \eta \mu o \kappa \rho \alpha \tau i \alpha$, cuyo ad-

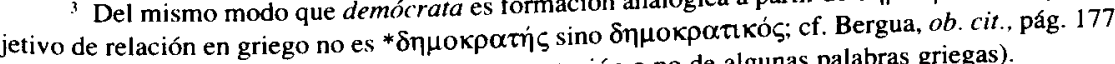
(con algunos erroes en lo referente a la documentación o no de algunas palabras griegas).

${ }^{4}$ Para el caso de acrobate, acuñado en francés antes de estar atestiguado (epigráficamente) en griego, cf. F. R. Adrados, «Los orígenes del lenguaje científico», Revista Española de Lingüística 27, 2 (1997), págs. 299-315. 
mordialmente latino» y no llega a explicar de dónde procede el sentido transitivo de - 'geno ( «que causa o produce $\mathrm{x}$ )) en voces como patógeno, cancerígeno, etc. (pág. 280). No es de extrañar esta confusión, que aparece en muchos diccionarios y obras de consulta; sin embargo, la realidad es que estamos ante

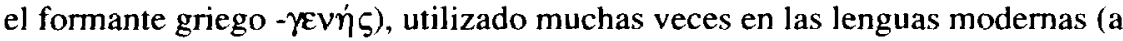
partir del siglo XVIII) con un valor transitivo que no tenía nunca en griego; la terminación española en -ola se explica fácilmente a partir de la francesa en - $e$ (patogène, etc.). Para más detalless históricos, remitimos a las páginas que a

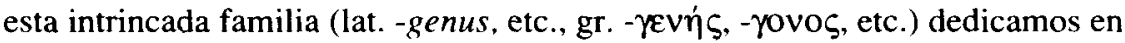
nuestra Introducción citada ${ }^{5}$.

Por otra parte, en general se alude, aunque sea sumariamente, a un aspecto importante como es la acentuación de todos estos helenismos. Por ejemplo, en la entrada correspondiente a -tipo se señala que los compuestos con este lexema son llanos por influencia de la palabra suelta tipo, cuando deberían ser esdrújulos según las normas que regulan el acento de los helenismos cultos españoles (a través del latín); etc. Lo único que se echa en falta en este apartado es haber tenido más en cuenta la influencia de la acentuación francesa, pues es esta lengua la que anda muchas veces detrás de helenismos llanos que deberían en principio ser esdrújulos y viceversa ${ }^{6}$.

Antes de pasar a los sufijos de origen griego más productivos, hay que aludir a la inclusión de una curiosa serie de terminaciones átonas de orígenes muy heterogéneos, como son -'ago, -'alo, -'ano, -'aro, terminaciones que han conseguido «extenderse, por analogía, a un pequeño grupo de palabras en las que parecen desempeñar el papel de una ampliación semánticamente vacía» (pág. 82), y que nosotros no incluimos en nuestra lista de sufijos de origen griego. Entre los diversos antecedentes de esas terminaciones españolas aparecen algunos helenismos latinos (espárrago, estómago, piélago y tártago; búfalo, címbalo, crótalo, escándalo, sándalo y algunos más; rábano, cuévano, huérfano, órgano y varios más; ásaro, bárbaro, cántaro, cítara, lámpara, etc.). Desde el punto de vista adoptado por el diccionario de Pharies quizá esté justificado dedicarles una entrada propia; desde el punto de vista histórico del griego, se trata o bien de terminaciones relativamente poco productivas, y cuya presencia en unos pocos helenismos españoles difícilmente hubiera bastado para hacer de ellos sufijos propiamente dichos, como - $\alpha \lambda \mathrm{o}$ - (cf. $\alpha \pi \alpha \lambda o ́ \zeta, ~ o ́ \mu \alpha \lambda o ́ \varsigma$,

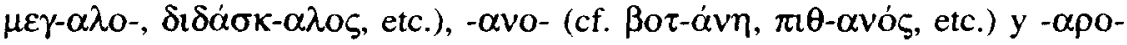

s Bergua, ob. cit., págs. 292-295.

- Cf. especialmente V. García Yebra, Diccionario de galicismos prosódicos y morfológicos, Madrid, 1999. 
(cf. ve- $\alpha \rho o ́ \zeta)^{7}$, o bien, en el caso de -'ago, vemos que se mezclan algunas voces griegas realmente terminadas en - $\alpha \gamma o-$ (espárrago, piélago) con otras en las que esa terminación es resultado de la evolución fonética romance (como estómago < lat. stomachus < $\sigma \tau$ tó $\mu \alpha \chi 0 \zeta$ ) u otro tipo de alteraciones.

Entrando ya en los sufijos griegos propiamente dichos, encontramos algunas objeciones que hacer acerca de su inclusión o de la forma de alfabetizarlos. Por ejemplo, ¿tiene sentido incluir el -ito de sulfito, lignito, etc., dentro de la entrada correspondiente al diminutivo -ito, teniendo en cuenta sus orígenes y significado tan distintos? ¿No sería más claro abrir una entrada propia para cada uno? Lo mismo cabe decir de -eo (caldeo, europeo, etc.), incluido en la entrada correspondiente al -eo deverbal (paseo, meneo, etc.). ¿Por qué se dedica una entrada a -sis, a pesar de reconocer que, a diferencia de -osis e-iasis, «carece de sentido propio y, por consiguiente, de estatus sufijal» (pág. 474)? Pues, de acuerdo con este criterio, también debería tener una entrada, por ejemplo, -ma (cf. estig-ma, progra-ma, etc.), que sólo es productivo en las formas -ema y -oma.

Sobre cada uno de los sufijos griegos en particular —que aquí, a diferencia de Pharies, agrupamos de acuerdo con su origen morfológico en griego-, conviene hacer las siguientes observaciones (sólo entramos en las cuestiones que son, a nuestro juicio, de más calado):

- sobre -esco (relacionado etimológicamente con -isco), quizá podría decirse algo acerca de su valor apreciativo-despectivo en español ${ }^{8}$.

- sobre el sufijo -ía (gr. - $i \alpha$ ) hay que referirse a la acentuación. Lo primero que hay que decir es que Pharies parece suponer el mismo tratamiento para las palabras griegas terminadas en -i $\alpha$ y las en $-\varepsilon 1 \alpha$, cuando en realidad lo lógico es que, de acuerdo con las normas de la prosodia latina, el primer grupo dé como resultado en español - 'ia (como en íơopi $\alpha>$ historia) y el segundo -ía ( $\dot{\lambda} \lambda \varepsilon \gamma \varepsilon i \alpha>$ elegía). Aparte de esto, la cuestión importante es saber cómo y cuándo se difundió en castellano (y en italiano) la terminación -ía, hasta el punto de convertirse en un sufijo muy productivo (cf. lozanía, alcaldia, etc.). Y es que Pharies se suma a la explicación de Meyer-Lübke, Grandgent, Lumpe y otros, según la cual fue sobre todo en el latín cristiano donde muchas palabras griegas y luego latinas pasaron a pronunciarse con esa acentuación en -ía (en vez de - $i a$, que era la propia del latín culto en palabras como philosophia, etc.),

7 Para información detallada sobre estas terminaciones griegas, cf. E. Schwyzer, Griechische Grammatik, I, Múnich, 1950, págs. 481-484, 489-490.

${ }^{8}$ Remitimos a Bergua, ob. cit., págs. 256-257. 
punto de partida para que -ía se acabara sintiendo como un auténtico sufijo aplicable a voces romances (lozano $>$ lozanía) ${ }^{9}$. Sin embargo, hay otra explicación que, si no anula, sí al menos puede matizar la recién mencionada, y es la que explica la proliferación de palabras castellanas en -ía por influjo de las francesas correspondientes en -ie (astronomie, etc.) ${ }^{10}$, que a su vez, según Lüdtke, debían el cambio de acento a la reforma de la pronunciación del latín en tiempos de Carlomagno ". Se trata de un asunto muy complejo, pues a falta de un sistema de notación prosódica constante es difícil conocer la acentuación real de las palabras en épocas remotas (a no ser por noticias de los gramáticos o por la evidencia que proporciona la poesía rimada); en todo caso, probablemente valdría la pena investigarlo más a fondo habida cuenta de la importancia del sufijo en el español moderno.

- sobre -íco y los relacionados con él (-aico, -ático, -iaco, -ístico) conviene señalar que no es correcto lo que se dice acerca de la doble acentuación de -iaco/-iaco en casos como zodiaco, amoniaco, etc. («las variantes -iaco e íaco, de las cuales aquélla hereda su acentuación del latín y ésta imita al esdrujulismo de otras terminaciones de origen griego como -ófago", p. 299); en realidad es al revés, es -íaco la que responde a la acentuación latina (la /a/ de -iacus es siempre breve, como la / $\alpha /$ de -lokó $\zeta)$, mientras que la acentuación en -iaco se explica por la tendencia natural del español a diptongar en esas situaciones (como ocurre también en otros helenismos como Iliada/llíada, Olimpiada, etc.) ${ }^{12}$. Tampoco tiene sentido incluir pacífico (lat. paci-ficus < pax, pacis + facio) entre las palabras formadas con el sufijo - ico, por más que el hablante común pueda efectuar mentalmente ese falso corte.

- el sufijo - ido está mal identificado en voces como félido, cánido, etc. (éste es uno de los errores más frecuentes en diccionarios etimológicos españoles), donde no tiene nada que ver con lat. -idus (heredado en cálido, nítido, etc.), sino con el sufijo patronímico griego -ions, a través del latín -idae (en plural), con posterior cambio de terminación en español (- $i d o / a)$ por influencia probable del francés ${ }^{13}$.

- sobre los derivados del sufijo de agente griego - $\tau$ h, es decir, -ita (e -ito), -ista, -ota (a los que en nuestra Introducción se daba un tratamiento con37 y 146 .

${ }^{9}$ Cf. por ejemplo C. H. Grandgent, Introducción al latín vulgar, trad. esp., Madrid, 1970, \$

10 Así en García Yebra, ob. cit., págs. 99-120, explicación aceptada quizá con demasiada rapidez en Bergua, ob. cit., págs. 107-108 y 240-41.

$"$ Cf. H. Lüdtke, Historia del léxico románico, trad. esp., Madrid, 1974, págs. 89-90.

12 Cf. Bergua, ob. cit., pág. 104.

13 Para los detalles, Bergua, ob. cit., págs. 232-234. 
junto para destacar su origen común), hay que señalar sobre todo que a nuestro juicio no están bien explicadas del todo las causas de la proliferación de -ita en el griego y latín cristianos, así como de su uso para gentilicios; y es que, por un lado, la terminación -ím para crear gentilicios (sibarita, abderita, etc.), y por otro, la proliferación de -i $\tau$ \ fuera del griego pagano se remonta más allá del «griego patrístico y el latín eclesiástico» (Pharies, p. 362), pues su auténtico origen es la traducción de los LXX (Septuaginta), bastante antes por tanto del cambio de era ${ }^{14}$.

- en el caso de -oide, uno de los sufijos más interesantes entre los de origen griego, se echa en falta una explicación histórica de cómo ha cobrado el valor tan marcadamente despectivo que tiene en el español actual (infantiloide, etc.) ${ }^{15}$.

Otra cosa que se echa de menos en el diccionario - aunque somos conscientes de que es un campo muy difícil y que quizá sea pedir demasiado- es algo de información respecto al calco y a la influencia latente de los sufijos griegos sobre los latinos e indirectamente sobre los españoles; así, a título de ejemplo, en la entrada correspondiente a -oso podría indicarse que la gran abundancia de derivados latinos en -osus se debe en buena medida al calco de

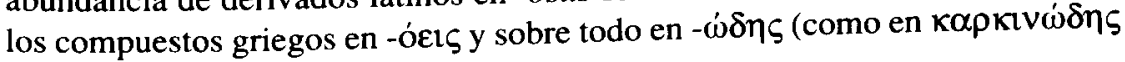
$>$ cancerosus, etc.) ${ }^{16}$.

En definitiva, se trata sin duda de una obra muy importante para todos los interesados en la morfología histórica del español, y que, con las salvedades que hemos señalado por lo que se refiere a los sufijos de origen griego, habrá de convertirse en utilísima herramienta tanto para hispanistas como para helenistas y latinistas interesados en estudiar la continuidad de estas lenguas en el español.

${ }^{14}$ Cf. Bergua, ob. cit., pág. 213.

15. Es lo que se trata de hacer en Bergua, ob. cit., págs. 264-270.

is Cf. Bergua, ob. cit., págs. 306-308, con la bibliografía básica al respecto. 